\title{
Systematic
}

\section{Discrimination of Advanced Hydrogen Production Technologies}

\section{INCOSE 2010}

Charles V. Park

Michael W. Patterson

\section{July 2010}

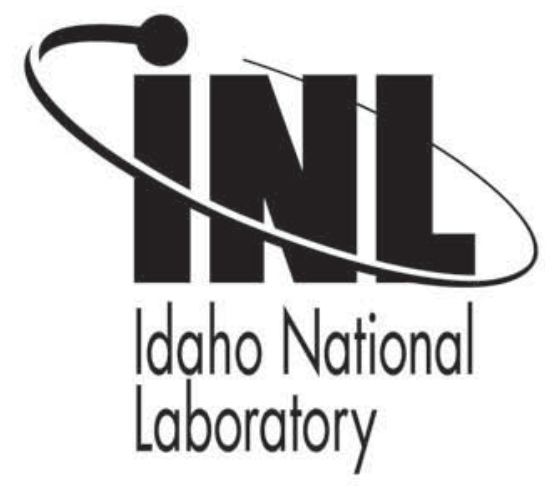

This is a preprint of a paper intended for publication in a journal or proceedings. Since changes may be made before publication, this preprint should not be cited or reproduced without permission of the author. This document was prepared as an account of work sponsored by an agency of the United States Government. Neither the United States Government nor any agency thereof, or any of their employees, makes any warranty, expressed or implied, or assumes any legal liability or responsibility for any third party's use, or the results of such use, of any information, apparatus, product or process disclosed in this report, or represents that its use by such third party would not infringe privately owned rights. The views expressed in this paper are not necessarily those of the United States Government or the sponsoring agency. 


\title{
Systematic Discrimination of Advanced Hydrogen Production Technologies
}

\author{
Charles V. Park \\ Idaho National Laboratory \\ P.O. Box 1625 \\ Idaho Falls, Id. 83415 \\ (208) 526-1091, Charles Park@INL.gov
}

\author{
Michael W. Patterson \\ Idaho National Laboratory \\ P.O. Box 1625 \\ Idaho Falls, Id. 83415 \\ (208) 526-5525, MW.Patterson@INL.gov
}

Copyright $@ 2010$ by Battelle Energy Alliance, LLC. Published and used by INCOSE with permission.

\begin{abstract}
The U.S. Department of Energy, in concert with industry, is developing a high-temperature gas-cooled reactor at the Idaho National Laboratory (INL) to demonstrate high temperature heat applications to produce hydrogen and electricity or to support other industrial applications. A key part of this program is the production of hydrogen from water that would significantly reduce carbon emissions compared to current production using natural gas. In 2009 the INL led the methodical evaluation of promising advanced hydrogen production technologies in order to focus future resources on the most viable processes. This paper describes how the evaluation process was systematically planned and executed. As a result, High-Temperature Steam Electrolysis was selected as the most viable near-term technology to deploy as a part of the Next Generation Nuclear Plant Project.
\end{abstract}

\section{Background}

Current U.S. energy challenges include: (1) the rising cost of fossil fuels, (2) dependence on unstable foreign sources for many of these fuels, (3) concerns about greenhouse gas (GHG) emissions, and (4) using fossil fuels for hydrogen production. Ninety percent of the hydrogen produced in the United States comes from the steam reforming of natural gas. This hydrogen is used to produce fertilizer (45\%) and to "sweeten" heavy-grade crude oil at refineries (45\%). For these reasons, the U.S. Department of Energy (DOE) in concert with industry is developing a high-temperature gas-cooled reactor (HTGR) to provide process heat and power that can produce hydrogen from water.

The demand for nuclear power is increasing to support industrial applications involving electricity, high-temperature heat, steam, hydrogen, and oxygen. This increase will accelerate as the real cost of carbon emitting technologies is accounted for. To achieve energy security and stability, the U.S. Energy Policy Act of 2005 (EPAct) defined a strategy to demonstrate an HTGR. Since then, DOE has led a sustained effort to develop this next generation of clean, safe, proliferation-resistant nuclear power.

Specifically, to implement EPAct, the Idaho National Laboratory (INL) is developing the Next Generation Nuclear Plant (NGNP) project as a public/private partnership with industry. The project is currently in the conceptual design stage and is planned to be operational in 2021 with a 60-year design life. NGNP will be licensed by the U.S. Nuclear Regulatory Commission and will meet or exceed current nuclear standards in reliability, nonproliferation, waste management, and security. The helium-cooled reactor outlet temperature is planned to be between 750 and $800^{\circ} \mathrm{C}$. Figure 1 presents a schematic of the NGNP. 


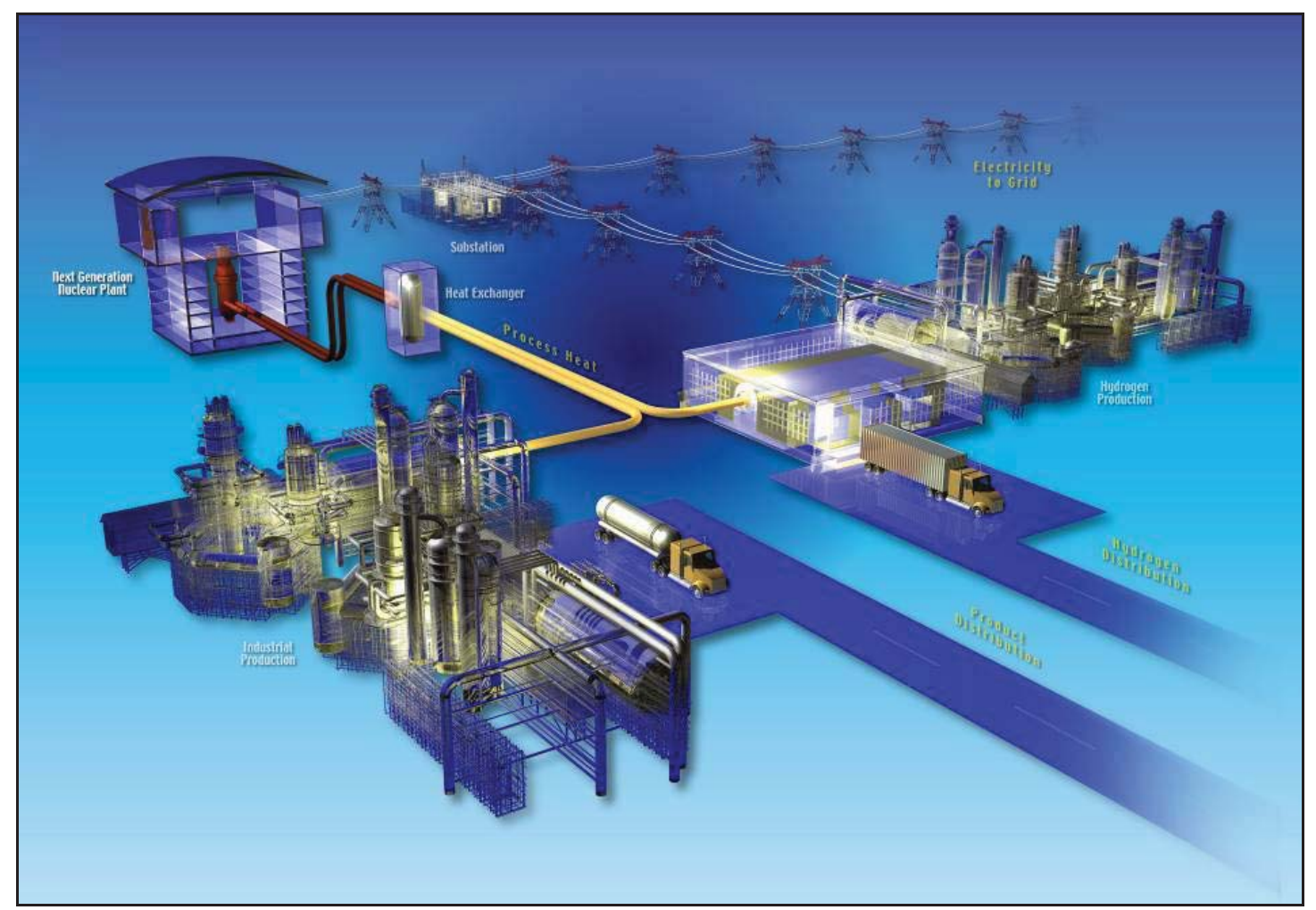

Figure 1. Schematic of the Next Generation Nuclear Plant.

Today, industry burns fossil fuels to provide the majority of its power and processing heat. About 450 nuclear power reactors operate worldwide, of which 103 are in the United States. The maximum reactor outlet temperature for these plants is around $300^{\circ} \mathrm{C}$. As shown in Figure 2, light water reactors (LWRs) can support applications such as desalination, district heating, ethanol concentration, and some petroleum refining. However, an HTGR with temperatures up to $800^{\circ} \mathrm{C}$ can support a variety of industrial applications requiring both clean and reliable hydrogen and/or high-temperature heat. Extending the outlet temperature to $950^{\circ} \mathrm{C}$ could also support coal gasification.

The production of hydrogen from water is being developed by a number of countries (including the United States) using electrolysis, and/or thermochemical processes. In 2008, it was determined that up to $\$ 24 \mathrm{M}$ could be saved by focusing limited funding on a primary technology with a backup rather than continuing to advance the three most promising technologies simultaneously. In 2009, the INL led an effort to systematically evaluate and select the best technology for deployment with NGNP. This paper describes that trade study. 


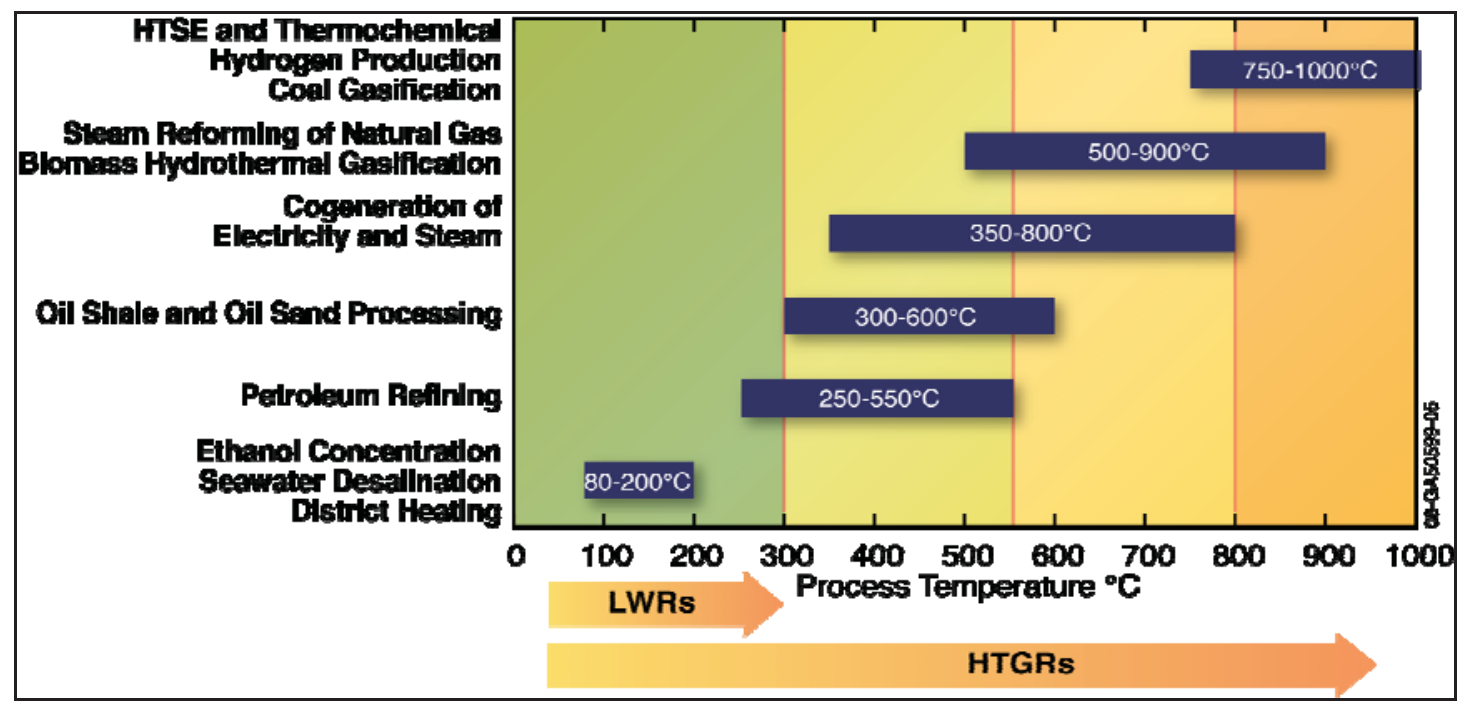

Figure 2. Required temperatures for process heat applications.

\section{Nuclear Hydrogen Production}

The annual U.S. demand for hydrogen is over 12 million tons and is expected to grow to over 30 million tons by 2030 [EIA/DOE, 2008]. Current and future hydrogen production and storage favor large facilities that compliment the characteristics of nuclear power plants. As detailed below, hydrogen can be produced by various processes, all of which may benefit from using an HTGR as the primary energy source:

- Conventional water electrolysis is a well-commercialized technology. Carbon emission from this form of hydrogen generation depends on the source of the electricity. When nuclear energy is used, those emissions are eliminated.

- High-temperature steam electrolysis is an advanced technology currently under development. This technology reverses the process of solid oxide fuel cells to produce hydrogen from steam. When coupled to an HTGR, this process can potentially double efficiencies to $50 \%$ (lower heating value) compared to conventional electrolysis.

- A number of thermochemical water splitting cycles have been identified in recent years. These cycles essentially split water into hydrogen and oxygen through a series of heat-driven chemical reactions. Laboratory testing of the leading cycles is under development in the United States, Canada, Japan, France, and other countries. In these thermochemical processes, only water, heat, and electricity are needed to produce hydrogen and oxygen. Most of the current U.S. development work has focused on the sulfur-iodine (SI) process.

- Hybrid cycles combine the benefits of thermochemical and electrolytic reactions for water splitting. This emerging technology offers the possibility of lower reaction temperatures by using electrolysis as a substitute for one of the chemical reactions.

- In the United States, steam methane reforming (SMR) is widely deployed to produce over 3 billion standard cubic feet (scf) of hydrogen per year, while consuming over 1.2 billion scf of natural gas [EIA/DOE, 2008]. The SMR reaction (Eq. 1) is endothermic and, therefore, does not generate $\mathrm{CO}_{2}$. The reforming heat, however, is supplied through 
combustion of approximately $20-30 \%$ of the methane, which generates $\mathrm{CO}_{2}$, a GHG. Furthermore, to increase the hydrogen yield, the syngas generated during reforming is shifted with water (Eq. 2) to produce $33 \%$ more hydrogen by converting all the original methane carbon to $\mathrm{CO}_{2}$.

$$
\begin{gathered}
\mathrm{CH}_{4}+\mathrm{H}_{2} \mathrm{O} \rightarrow \mathrm{CO}+3 \mathrm{H}_{2}+\text { combustion products including } \mathrm{CO}_{2} \\
\qquad \mathrm{CO}+3 \mathrm{H}_{2}+\mathrm{H}_{2} \mathrm{O} \rightarrow \mathrm{CO}_{2}+4 \mathrm{H}_{2}
\end{gathered}
$$

The overall result is that the mass of $\mathrm{CO}_{2}$ produced is 10.6 times the mass of hydrogen produced [Koroneos, et al. 2004]. However, an HTGR can provide the heat energy for the SMR process eliminating nearly $30 \%$ of the natural gas used, reducing carbon dioxide emissions, and increasing methane to hydrogen conversion efficiencies to $80 \%$.

\section{Trade Study Methodology}

The evaluation and down-selection of hydrogen production technologies was an essential step to focusing limited project resources. This down-selection, however, would have a significant impact on future research planned by developers including national laboratories, industry and other countries. This was a high-visibility, high-impact trade study. For this reason the planning and execution would have to be transparent, informed and above reproach.

In order to ensure a comprehensive, objective, defensible analysis, and useful results, nearly two months were spent developing a formal Hydrogen Technology Down-Selection Plan [Park et al. 2009]. This plan defined the objectives, assumptions, process, resources, cost and schedule required to execute the evaluation and selection. The evaluation methodology followed a standard systems engineering decision process, as shown in Figure 3 and described below.

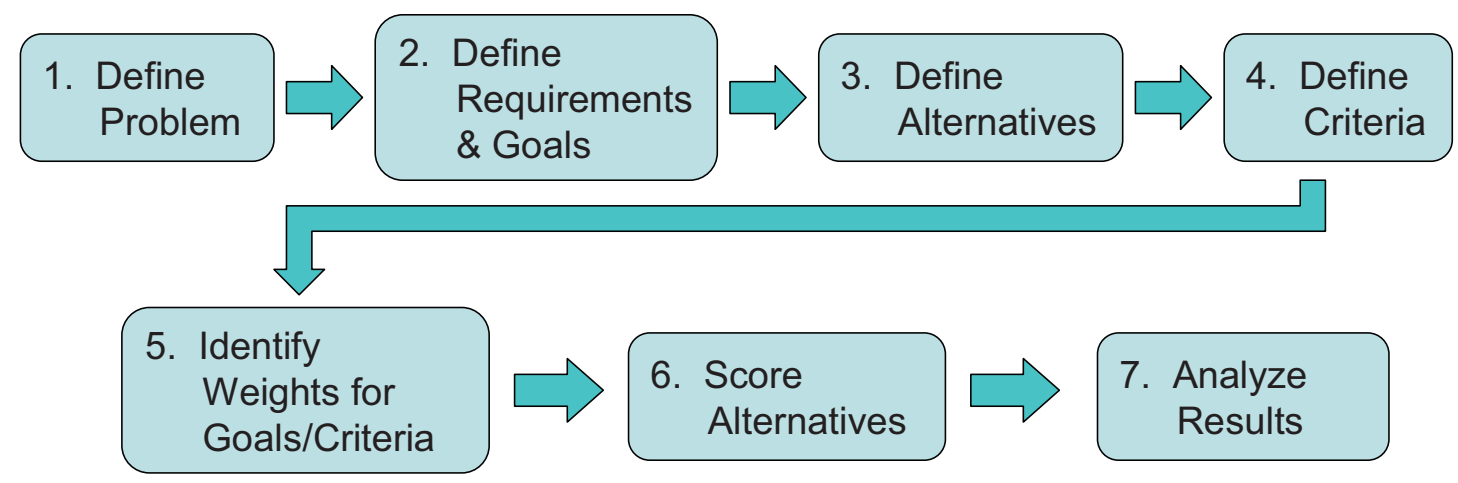

Figure 3. Systematic Selection Methodology

Problem Statement. It was necessary to focus limited research and development (R\&D) funds on the most viable hydrogen production technologies for deployment with NGNP. The problem statement was:

Aggressive NGNP $R \& D$ schedule and limited $R \& D$ funding require near-term selection of the most viable hydrogen production technologies.

Requirements and Goals. A first step defined the technical baseline under which each of the candidate technologies could be evaluated. Each of the technologies had optimized their process to some degree by selecting their most favorable operating condition. A fair comparison required that 
a standard set of operating conditions be set without unfairly penalizing some technology. A number of recent technical reports and the NGNP project baseline were used to define these parameters. Requirements included:

- Up to $600 \mathrm{MWt}$ per reactor unit

- 750 to $800^{\circ} \mathrm{C}$ Initial Reactor Outlet Temperature (ROT)

- $\quad 7 \mathrm{MPa}$ Reactor Outlet Pressure

- Helium Primary Coolant

- Graphite Moderated

- Pebble-Bed or Prismatic Reactor Core

- 60-year Design Life

- Scheduled Startup 2021

The hydrogen production technology will interface with the NGNP via an intermediate heat exchanger (IHX) or steam generator. These interface parameters are:

- Utilize up to $50 \mathrm{MWt}$ total reactor power with any electric conversion at $40 \%$

- He IHX outlet to the hydrogen process at $700^{\circ} \mathrm{C}$ and $7 \mathrm{MPa}$ pressure

- Outlet temperature from steam generator up to $550^{\circ} \mathrm{C}$ at $15 \mathrm{MPa}$ pressure

- Assume no contaminants that would effect the safety or operation of the hydrogen process are introduced at or upstream of this interface.

The overall goals for hydrogen production technologies included areas of performance, cost and risk:

\section{Performance}

- Maximize hydrogen production rate and efficiency as a function of energy input

- Maximize the utilization of energy produced by NGNP (electric power, steam and process heat)

- Maximize the potential for meeting end-user hydrogen product purity requirements

- Maximize the number of potential hydrogen applications that can utilize the hydrogen produced by NGNP or futures HTGRs

- Minimize unacceptable waste management issues

$\underline{\text { Cost }}$

- Minimize the cost of hydrogen per $\mathrm{kg}$

- Minimize development costs

$\underline{\text { Risk }}$

- Maximize deployment probability by 2021.

The NGNP reactor core type has not been specified, but the reference design includes: 
Define Alternatives. The three most mature hydrogen production technologies were the focus of this trade study. The first is Hybrid Sulfur (HyS), which is being developed jointly by Savannah River National Laboratory and Sandia National Laboratory. The second is Sulfur Iodine (SI), which was being developed jointly by General Atomics, Sandia National Laboratory, and CEA (France). The third is High Temperature Electrolysis (HTE), which is being developed by INL.

DOE has funded research in nuclear hydrogen production since 2003 resulting in these three technologies (at or near integrated laboratory scale). A number of studies (including a Nuclear Energy Research Initiative project by University of Kentucky, General Atomics, and Sandia National Laboratory) investigated the most promising technologies to guide DOE's nuclear hydrogen program. Other technologies have been pursued (such as copper-chloride and calcium-bromine cycles), but these have not advanced as far as the three technologies that were evaluated. Furthermore, other potential technologies may exist, either in the United States or internationally, but did not appear to be as mature as these three for near-term deployment with NGNP.

Develop Criteria. Perhaps the most crucial step in the trade study was selecting appropriate and useful evaluation criteria that would:

- Differentiate between alternatives

- Relate to project goals, objectives, and values of DOE and other stakeholders

- Be reasonably measurable or estimable

- Be independent of each other

- Be well understood by decision makers.

A detailed, systematic, and exhaustive review was made of relevant source documents to identify potential criteria and weighting. In this way, a comprehensive list of process characteristics and attributes was identified to ensure that the final selection criteria did not omit some important feature. Pertinent information from each document was then summarized, and similar, interdependent, and redundant criteria were combined. In addition to identifying potential criteria, the review also identified constraints and general assumptions which applied to all three technologies. As a result, the following decision criteria were established allowing the technology performance to be evaluated as a function of production cost, development cost, and deployment risk.

Table 1. Proposed Criteria and Weighting

\begin{tabular}{|c|c|c|}
\hline & Goal Weight & Criteria Weight \\
\hline Performance & 30 & 10 \\
\hline Quantity of Hydrogen Produced & & 5 \\
\hline Purity of Hydrogen Produced & & 10 \\
\hline Flexibility of Application & & 5 \\
\hline Waste Management & & \\
\hline Cost & 35 & 15 \\
\hline Cost of Hydrogen & & \\
\hline
\end{tabular}




\begin{tabular}{|c|c|c|}
\hline Validity of H2A Assumptions & & 10 \\
\hline Development Cost & & 10 \\
\hline Risk & 35 & 15 \\
\hline Technical Maturity & & 20 \\
\hline Development Risk & & 100 \\
\hline
\end{tabular}

Assign Weighting. Potential weighting was assigned to each criterion by INL to accentuate those characteristics determined to be the most important to the selection. Although weightings were preliminarily assigned, the Independent Review Team would modify these during the trade study workshop to refine criteria definitions and to highlight key characteristics. The document Maintaining a Technology-Neutral Approach to Hydrogen Production Process Development Through Conceptual Design of the Next Generation Nuclear Plant was developed, approved, and issued to guide the evaluation.

\section{Role of Independent Review Team (IRT)}

An IRT was selected by the INL and then approved by DOE-NE to evaluate the three candidate technologies and make down-selection recommendations. The team consisted of five members with backgrounds in academia and industry, and complementary technical expertise in hydrogen production, nuclear plant operations, hydrogen infrastructure, and technology development in general.

The IRT was selected based on the following predefined criteria:

1. Up to five members total

2. Two or three members from a hydrogen production related industry

3. Two or three members from a hydrogen production related university program

4. Members recognized in the hydrogen field as credible

5. Members have hydrogen related experience and education

6. Members are available from April through June 2009 including a trip the week of June 22 nd

7. No conflicts of interest exist with any of the candidate technologies

Each of the technology leads were asked to recommend hydrogen experts. DOE-NE and NGNP also provided candidate names. In addition, internationally recognized experts were included from organizations such as the National Hydrogen Association. Sixteen candidates were identified and the list was vetted to eliminate any participants that might not fully meet the membership or qualification criteria. None were eliminated. Candidate biographies were collected along with their education and professional experience. The candidates were prioritized to allow the first calls to be to those candidates that had the best overall qualifications. The technical leads and the sponsors provided their recommendations. In one case, two of the technology leads recommended the same person. This candidate was therefore placed high on the list. In another case, a candidate worked for the Federal government and was placed lower on the list. In one case, a candidate 
worked in industry but was also an adjunct professor so was placed high on the list. INL procurement contacted the candidates to determine their interest, availability, and the lack of conflict of interest. In one case a candidate declined due to a conflict of interest regarding one of the technologies. In one case, a substitute from the same organization was contacted because this person had more experience with hydrogen production. Not all of the candidates were contacted due to five members having been found to be qualified, interested, available, and nonbiased prior to reaching the end of the sixteen-candidate list. All of the contract documents and negotiations were conducted by INL procurement personnel.

The contracted members of the IRT were:

- Robert D. Varrin, Jr. (Team Lead), Dominion Engineering, Inc.

- Kenneth Reifsnider, University of South Carolina

- David Sandborn Scott, University of British Columbia

- Patricia Irving, InnovaTek

- Gregory A. Rolfson, Entergy, Inc.

The following specific tasks and activities were completed in the down-selection process:

1. INL prepared a Hydrogen Technology Down-Selection Methodology, Criteria and Weighting Plan. This Plan was subsequently approved by DOE-NE [3] and reviewed by the IRT.

2. INL identified Technology Leads independent from the IRT to compile and summarize information on each of the three candidate technologies. These Leads were identified based on their past experience in the development of the technologies both in the US and internationally. The Technology Leads coordinated the preparation of written Technology Summaries for review by the IRT members prior to the formal presentations to the IRT.

3. INL provided the IRT with background documents and references on NGNP, HTGR, and each of the three main hydrogen production technologies as well as some background on alternative technologies that have or are still being considered for use with HTGRs or LWRs. This included references pertaining to alternative processes such at the $\mathrm{Cu}-\mathrm{Cl}$ and Ca-Br cycles.

\section{Down-Select Workshop}

INL sponsored a 5-day workshop from June 21 to June 26 in Denver, Colorado during which the following activities were completed.

- A review of the Down-Selection Plan was conducted and a discussion of methodologies, criteria, and weightings that would be used in the subsequent evaluations was completed on the first day.

- Presentations by each of the Technology Leads with support from other experts, as required. Approximately 2 to 3 hours was allowed for follow up questions and answers. In some cases, the Technology Leads were requested to provide additional supporting information after the meeting. 
- At the end of each presentation day, the IRT developed initial scores for the technology described that day. The scores were based on the criteria and weightings for the three project goals described in the Down-Selection Plan: (1) performance, (2) cost, and (3) risk.

- The last two days involved lively interactive evaluations and summarized technical issues associated with each technology. The IRT considered the following specific items during the evaluation:

- Significant technical challenges for each technology. Typically, the IRT identified from between 20 to 40 issues for each technology. The IRT then graded these issues in terms of risk

- Past technical uncertainties

- Major advantages of the technology as compared to the others

- Recent accomplishments

- "Short-term" R\&D needs, that if completed successfully, would reduce the uncertainty in the risk of continued development

- Opportunity costs of abandoning any of the technologies in favor of another.

- In a separate evaluation, the impact of ranking each of the three technologies in terms of the suitability for integration with NGNP with a 750 to $800^{\circ} \mathrm{C}$ outlet temperature was performed. This was discussed in light of the potential that future HTGRs may operate at temperatures up to $950^{\circ} \mathrm{C}$.

- Also considered was the progress on the development of each technology to date in terms of funding it has received. More specifically, attempts were made to levelize the maturity of the process in light of the funding received. While no evaluation of this kind is perfect, the IRT did not want to penalize a technology for not having achieved an R\&D or programmatic milestone as a result of significantly less funding or less development time.

- After reviews of the detailed assessments described above, a more quantitative scoring or grading of the three technologies was performed based on the INL data analysis. Some refinement to the proposed weightings and criteria were incorporated into the final scoring sheets and the technologies were then scored and ranked.

\section{Conclusions and Results}

The IRT completed its assessment of the candidate advanced hydrogen production technologies considered for integration into NGNP and submitted a formal report with the following conclusions:

1. Given that each technology has been the focus of many years of R\&D in the United States and abroad, all three technologies were concluded to be worthy of consideration for integration in the NGNP. All three technologies have consistently been selected as the leading candidates for nuclear hydrogen production out of the hundreds of technologies or cycles that have been proposed. 
2. The IRT ranking indicates that HTSE is the hydrogen production technology that presents the greatest potential for successful deployment and demonstration at NGNP. This conclusion is primarily based on the following points:

a. Limited or no use of intermediate chemicals (such as iodine or sulphuric acid)

b. Less complex design

c. Overall progress to date

d. Inherent efficiencies which are less sensitive to operating temperature, a feature that is particularly relevant with NGNP operation beginning at a relatively low HTGR temperature of 750 to $800^{\circ} \mathrm{C}$

e. The ability to build upon billions of dollars in SOFC research that has been completed or is pending

f. The intrinsic knowledge of many of the fundamental chemical and physical processes involved in the technology

g. Several novel design features that have been incorporated into the latest laboratory-scale demonstration tests including integral recuperators (which may or may not be used in the final HTSE design for NGNP)

h. The ability to accommodate load-following, as well as timely startup and shutdown time requirements

i. The potential for mass production of HTSE components which could be advantageous with respect to the long term life-cycle costs as compared to the other two leading candidates

3. Both HyS and SI processes exhibit attractive attributes for hydrogen production that supports not abandoning either technology for future consideration. Specifically, it would be prudent to continue their development through the funding of well defined R\&D projects of lesser scope than those dedicated to HTSE. The IRT identified between 10 to 15 short term R\&D needs for each technology.

4. If faced with a choice between funding short term R\&D for either HyS or SI, but not both, the DOE should consider as a minimum giving higher priority in any R\&D to topics that benefit both of these technologies such as continued development and modeling of the sulfuric acid decomposer.

5. DOE-NE should discuss the manner in which short term R\&D needs that were identified by the IRT be pursued through coordination with private entities or international organizations.

The final scoring sheet is shown in Table 2 . 
Table 2. Hydrogen Production Technologies Final Scoring

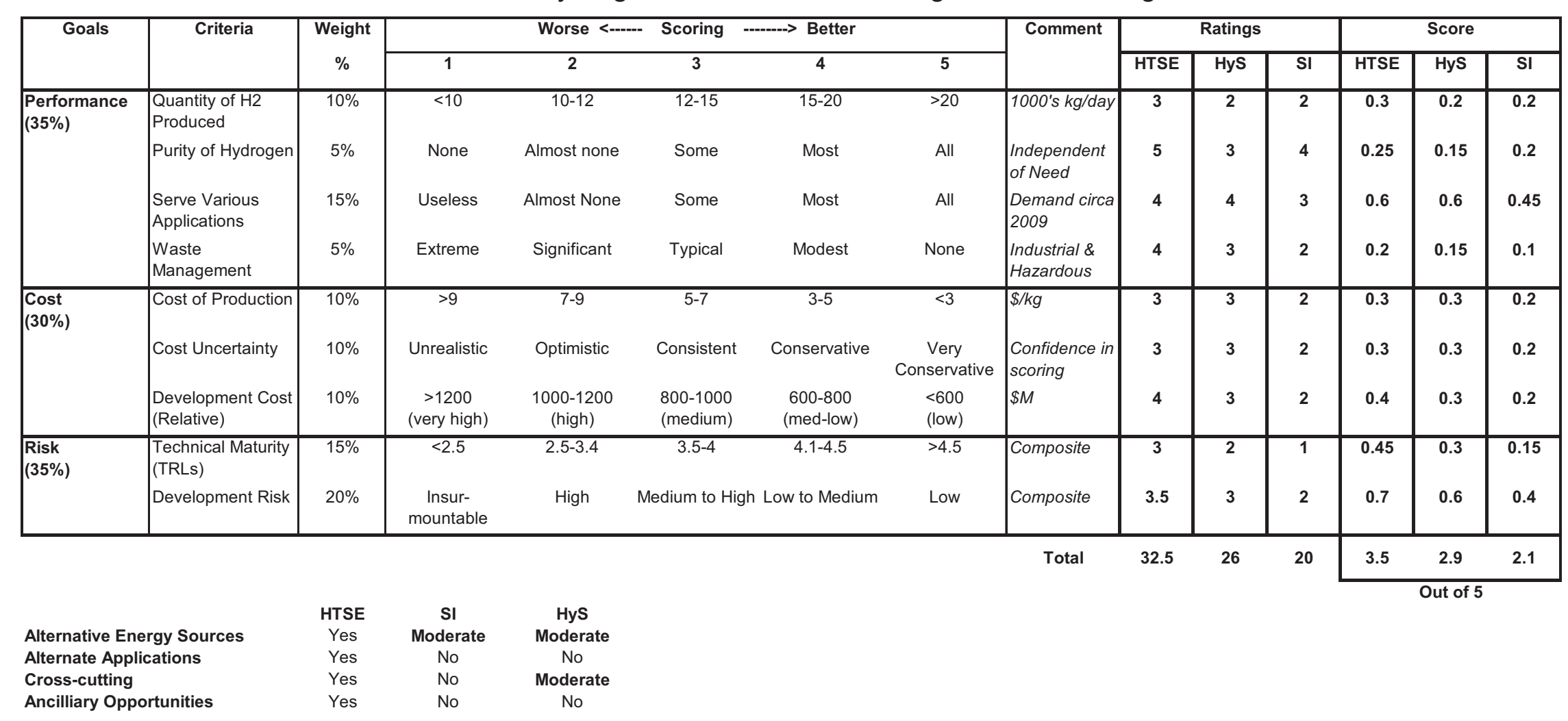




\section{References}

U.S. Department of Energy. 2008. The Impact on the Increased use of Hydrogen on Petroleum Consumption and Carbon Dioxide Emissions. EIA/DOE-Report \#SR-OIAF-CNEAF/2008-04 -August 2008-Appendix A.

Hydrogen Technology Down-Selection Plan. 2009. PLN-2985. Revision 1. March 26.

Koroneos, C., A. Dompros, G. Roumbas, and N. Moussiopoulos. 2004. Life cycle assessment of hydrogen fuel production processes. International Journal of Hydrogen Energy. 29. pp 1443-1450. January.

Lee, S., J. Speight, and S. Loyalka. 2007. The Handbook of Alternative Fuel Technologies. CRC Press. pages 218-219.

Maintaining a Technology-Neutral Approach to Hydrogen Production Process Development Through Conceptual Design of the Next Generation Nuclear Plant. INL/EXT-08-14193. Revision 1. May 2008

NGNP Hydrogen Plant Alternatives Study. 2009. NGNP-HPS SHAW-HPA. Revision 1. .

NGNP Technology Development Roadmaps: The Technical Path Forward. INL/EXT-08-15148. January 2009

Olah, G., A. Goeppert, and G. Prakash. 2006. Beyond Oil and Gas: The Methanol Economy. CA: Wiley-VCH Publications.

Probstein, R., and R. Hicks. 2006. Synthetic Fuels. New York: Dover Publications. Inc.

\section{Disclaimer}

This manuscript has been authored by Battelle Energy Alliance, LLC under Contract No. DE-AC07-05ID14517 with the U.S. Department of Energy. The United States Government retains and the publisher, by accepting the article for publication, acknowledges that the United States Government retains a nonexclusive, paid-up, irrevocable, world-wide license to publish or reproduce the published form of this manuscript, or allow others to do so, for United States Government purposes.

\section{Biography}

Charles Park is a Registered Professional Engineer who has worked at the Idaho National Laboratory (INL) since 1982, with an emphasis in Systems Engineering and Project Management. He currently supports the Next Generation Nuclear Plant (NGNP) and the production of hydrogen using nuclear power. Charles has also passed the Certified Systems Engineering Professional (CSEP) written exam and is awaiting verification of references. He is also a certified Project Management Professional with the Project Management Institute. He helped oversee construction of the Columbia Generating Station (a General Electric 1100 MWe Boiling Water Reactor) near Richland, Washington, and was a project engineer with a regional consulting engineering firm before that. He graduated from the University of Idaho with a Bachelor of Science degree in Civil Engineering in 1979. His essential skill is coaxing order out of chaos. 
Mike Patterson is the NGNP Engineering Technical Support Manager including hydrogen production, heat transport, heat exchangers, and industrial process applications. Mike has over 25 years experience in nuclear operations, engineering, research and development, and project management. He holds a Bachelor of Science degree in Mechanical Engineering from the University of Idaho and is a certified project management professional. 